\title{
Comparison of persistence rates of acetylcholine-esterase inhibitors in a state Medicaid program
}

\author{
Susan M Abughosh' \\ Stephen J Kogut ${ }^{2}$ \\ 'Department of Pharmaceutical \\ Sciences, Massachusetts College \\ of Pharmacy and Health Sciences \\ (MCPHS), MA, USA; ${ }^{2}$ Department \\ of Pharmacy Practice, Program \\ in Pharmacoepidemiology \\ and Pharmacoeconomics, University \\ of Rhode Island (URI), College \\ of Pharmacy, RI, USA
}

Objective: To compare levels of persistency between cholinesterase inhibitors (ChEIs) among a Medicaid patient population of older adults.

Methods: Survival analysis was used to assess differences in discontinuation between ChEIs (donepezil versus rivastigmine and galantamine), and for difference in patient gender, age, race, and care setting.

Results: Rates of discontinuation increased from $42.7 \%(95 \% \mathrm{CI}=39.9-45.5)$ at 12 months to $84.8 \%(95 \% \mathrm{CI}=82.3-87.3)$ at 24 months. In multivariate models, no significant difference in discontinuation existed prior to 365 days. However, patients dispensed donepezil were less likely to discontinue as compared with users of the other two ChEIs after the first year $(\mathrm{RR}=0.70 ; \mathrm{CI}=0.499-0.983 ; \mathrm{p}<0.04)$. Patients of white race were less likely to discontinue $(\mathrm{RR}=0.549 ; 95 \% \mathrm{CI}=0.43-0.82 ; \mathrm{p}=0.0015)$, while gender, care setting, and age were not associated with discontinuation.

Conclusions: One-year persistence rates were similar between different ChEIs. Among patients persisting with ChEI medication for at least 12 months, users of donepezil were slightly more likely to continue to persist at 24 months. Nearly half of patients failed to persist with ChEI therapy for at least 12 months. Our findings underscore the limitations of the ChEI medications and the urgent need for effective and tolerable therapeutic options for patients having dementia.

Keywords: persistence, elderly, alzheimer's disease, cholinesterase inhibitors, medicaid

\section{Background}

Alzheimer's Disease (AD) is an irreversible progressive disorder characterized by neuronal deterioration that results in loss of cognitive functions, such as memory, communication skills, judgment and reasoning (Lanctot et al 2003). It is a common (Fratiglioni 1993; Zuard 2001) and chronic dementia disorder among elderly people (Fratiglioni 1993), responsible for nearly 70\% of all dementias (Zuard 2001). Approximately 4.5 million Americans suffer from AD in the US population, and this number is expected to increase almost 3-fold, to 13.2 million by 2050 (Hebert et al 2003). The incidence and prevalence of $\mathrm{AD}$ increases exponentially between the ages of 65 and 85 , approximately doubling every 5 years of age (Rocca et al 1991). The proportion of new onset cases who are 85 years of age or older is expected to increase from $42 \%$ in 1995 to $62 \%$ in 2050 (Hebert et al 2001). In 1995, 7.1\% of all deaths in the US were attributable to $\mathrm{AD}$, placing it on a par with cerebrovascular diseases as the third leading cause of death (Ewbank 1999). The 1991 estimate of total prevalent cost of the disease was $\$ 67.3$ billion $(\$ 173,932$ per case), with $\$ 20.6$ billion in direct costs (\$47,581 per case) (Ernst and Hay 1994). It is a disease with significant economic burden and a high societal impact, with the proportion of older adults increasing in the population (Fratiglioni 1993; Hebert et al 2003). 
The FDA approved 4 cholinesterase inhibitor drug therapies for $\mathrm{AD}$ : tacrine, donepezil, galantamine, and rivastigmine, collectively known as acetyl-cholinesterase inhibitors (ChEIs). By inhibiting the breakdown of the enzyme acetylcholine-esterase, these agents are hypothesized to prolong the action of acetylcholine at the postsynaptic receptor by preventing its hydrolysis. Cholinesterase inhibitors are also prescribed for other conditions with cholinergic system dementia such as vascular dementia, Parkinson's disease and multiple sclerosis dementia (Kloszewska 2002). Though not curative, these medications can slow the progression of $\mathrm{AD}$ rather than reverse its progressive decline and have been shown to have a modest beneficial impact on neuropsychiatric outcomes for $\mathrm{AD}$ patients (Trinh et al 2003). The major therapeutic effect on ChEI is to maintain a cognitive function at a stable level during a 6- to 12-month period (Giacobini 2000a, b; Giacobini 2001a, b; Giacobini 2002). Additional drug effects are to slow down cognitive deterioration, improve behavioral problems, and increase ability to perform daily living activities (Jann 1998; Giacobini 2000a, b; Giacobini 2001a, b; Giacobini 2002) and improve the patient's mood (Grutzendler and Morris 2001). Recent studies show that the cognitive stabilization effect may be prolonged up to 24 (Giacobini 2000a, b; Giacobini 2001a; Giacobini 2002) to 36 months (Giacobini 2001b). The four therapies for $\mathrm{AD}$ differ by selectivity and specificity for the brain tissue, as well as the ability to interact with other drugs, adverse events on the nervous system and gastrointestinal tract, and hepatotoxicity (Zuard 2001). Tacrine is no longer marketed in the US because of safety precautions (Clark and Karlawish 2003), and donepezil was the most frequently prescribed ChEI (Auriacombe et al 2002; Bullock and Connolly 2002) at the time of the study.

Persistence to these agents is expected to be suboptimal, as patients are often poorly adherent to chronic medications (Barat et al 2001; McDonald et al 2002). In a number of chronic illnesses, noncompliance to medications has been shown to have a significant negative health impact (Luscher et al 1985; Col et al 1990; Psaty et al 1990; Chin and Goldman 1997; McDermott et al 1997; Bergen et al 1998; Paterson et al 2000; Tsuyuki and Bungard 2001), and is estimated to cost the US \$25 billion annually when indirect costs are included (Sullivan and Hazlet 1990). Older adults are especially prone to be non-adherent (Gray et al 2001) because of susceptibility to adverse events (Monane et al 1998; Golden et al 1999), deficits in physical dexterity, cognitive skills and memory, and because of the large number of medications they are prescribed (Cramer 1998). Some researchers have found that older patients are generally more likely than younger patients to discontinue their medication (Applegate 2002; Benner et al 2002; Jackevicius et al 2002). Patients may discontinue ChEI drug therapy as a result of intolerable adverse events, rapid clinical deterioration, or failure to improve, stabilize, or reduce the rate of decline in AD (Fillit and Cummings 2000). While persistence with specific ChEI medications has not been adequately examined by researchers, switching between different ChEIs has been frequently reported (Auriacombe et al 2002; Bullock and Connolly 2002; Emre 2002). There is limited information outside the clinical trial setting (Mauskopf et al 2005) and results of previous studies examining persistence to ChEIs have been inconsistent (Sicras and Rejas-Gutierrez 2004; Mauskopf et al 2005; Sicras-Mainar et al 2006) or have included only one type of ChEI (Roe et al 2002), thus preventing a comparison.

The objective of this research was to compare rates of persistence between donepezil and other types of ChEIs in usual care settings among a patient population of older adults enrolled in a state Medicaid program. Studies have reported donepezil to have better tolerability than the other ChEIs (Rogers et al 1998; Emre 2002; Inglis 2002; Wilkinson et al 2002; Birks 2006). Thus, we assessed persistence with each ChEI medications separately, and overall.

\section{Methods}

\section{Study population and design}

We conducted a retrospective cohort study among patients enrolled in the Rhode Island Medicaid program between January 1, 2001 and December 31, 2003, and who received at least one dispensing for a ChEI medication. New users of ChEIs were identified by selecting patients receiving an initial prescription for a ChEI medication between July 1, 2001 and December 31, 2003. Those included had no prior dispensing for a ChEI medication in the previous 6 months, and an initial prescription prior to June 30, 2003, such that all patients had at least 6-months of follow-up time. Cases were excluded if they were less than 50 years of age. Information describing demographic and other patient characteristics was made available. Members with greater than a 6-month period (180 days) between refills, or between the last refill and the end of the study period were considered to have discontinued the drug. Switching to other types of cholinesterase inhibitors was assessed separately among those that continued their medication at 6-months and at 1 year. 
Independent variables included class of ChEI dispensed (donepezil versus rivastigmine and galantamine), gender, age (age 50-69 years; or age 70 years or greater), race (white versus nonwhite), and care setting (long-term care setting versus community-dwelling). Categorizing age at 70 years was determined after performing an assessment of the parametric form for the age variable.

Descriptive statistics were used to determine the frequencies of various patient characteristics. Survival analysis was used to assess differences in persistence among ChEIs product dispensed, and by the patient characteristics identified above. Kaplan-Meier (KM) curves were independently constructed for each of the predictor variables (class of ChEIs, gender, age, race, setting) and the log-rank statistic was used to evaluate group differences in persistence. Extended Cox proportional hazards models were used to estimate rate ratios (RR) and 95\% confidence intervals (CI) for the association between patient characteristics and ChEIs discontinuation. Statistical analyses were carried out using SAS statistical package version 8.01 .

\section{Results}

A total of 1564 patients met the study's inclusion criteria. Baseline characteristics of the population are presented in Table 1 . The mean age of these patients was 83 years and $76 \%$ were female. Most of the patient population were in long-term care (LTC) (86\%) and 61\% where of white race. Donepezil was the most widely dispensed ChEI accounting for $56.4 \%$ of the patients.

Table 2 presents the discontinuation rates at 12 months and 24 months, overall and according to patient

Table I Characteristics of new users of cholinesterase inhibitor (ChEl) medications $(n=1564)$

\begin{tabular}{lll}
\hline Characteristic & & n (\%) \\
\hline Gender & Females & I I90 (76.I\%) \\
& Males & $374(23.9 \%)$ \\
Age (years) & Mean 83.I & \\
& SD 9.1 & \\
& $\geq 70$ & $1435(91.8 \%)$ \\
& $50-69$ & $129(8.2 \%)$ \\
Race & White & $956(61.1 \%)$ \\
& None-white & $75(4.8 \%)$ \\
Initial type of ChEl & Missing & $533(34.1 \%)$ \\
medication dispensed & Donepezil & $882(56.4 \%)$ \\
& Rivastigmine & $317(20.3 \%)$ \\
Setting & Galantamine & $365(23.3 \%)$ \\
& Long-term care & $1340(85.7 \%)$ \\
& Community & $224(14.3 \%)$ \\
\hline
\end{tabular}

Abbreviation: SD, standard deviation. characteristics. Overall discontinuation increased with time from $42.7 \%(95 \% \mathrm{CI}=39.9-45.5)$ at 12 months, to $84.8 \%(95 \% \mathrm{CI}=82.3-87.3)$ at 24 months. In univariate analyses, the initial type of dispensed ChEI medication was not associated with discontinuation $(p=0.22)$. During the first 12 months, males were more likely to discontinue than females $(\mathrm{p}=0.04)$ and whites were less likely to discontinue $(\mathrm{p}<0.0001)$ than non-white patients.

A small percentage of patients switched ChEI medication type during the study timeframe. Among patients who were started on donepezil and continued the medication for 6 and 12 months, 96\% remained on donepezil at 6 months and at 12 months. At 6 months, $1 \%$ switched to rivastigmine and $3 \%$ switched to galantamine and at 12 months $2 \%$ were receiving rivastigmine and $2 \%$ were receiving galantamine. Among patients who were started on rivastigmine $92 \%$ were still on rivastigmine at 6 months while $4.4 \%$ were switched to donepezil and 3.5\% to galantamine. At 12 months, $89 \%$ were still on rivastigmine, $7.8 \%$ were receiving galantamine and $3.2 \%$ were receiving donepezil. Finally, among patients who were started on galantamine, $98 \%$ remained on galantamine at 6 months, while $1.5 \%$ were switched to donepezil and $0.8 \%$ to rivastigmine. At 12 months, $98.7 \%$ of these patients were receiving galantamine and $1.3 \%$ were receiving rivastigmine. The Medicaid plan had no influence on drug switches, as no restrictions on the use of any particular ChEI medication were in place during the study timeframe.

In multivariate models, persistence rates did not differ among ChEI medication use as assessed during the first 12 months of therapy $(\mathrm{RR}=1.002 ; \mathrm{CI}=0.807-1.243$; $\mathrm{p}=0.9879$ ). Among those persisting for at least 12 months, users of donepezil were less likely to discontinue during subsequent months as compared with users of the other two ChEIs ( $R R=0.70 ; \mathrm{CI}=0.499-0.983 ; \mathrm{p}<0.0397$ ). Overall, patients of white race showed better persistence than of nonwhite race $(\mathrm{RR}=0.549 ; 95 \% \mathrm{CI}=0.43-0.82 ; \mathrm{p}=0.0015)$. This, however, was based on $66 \%$ of the population since $34 \%$ had missing values for race. Gender, care setting, and age were not associated with differences in discontinuation. These results are presented in Table 3. Figure 1 shows the survival curves for those dispensed donepezil vs other ChEI medications.

\section{Discussion}

Our findings suggest that discontinuation rates for ChEIs are high, as previously reported (Roe et al 2002; Sicras and Rejas-Gutierrez 2004; Mauskopf et al 2005; SicrasMainar et al 2006), and indicate slightly better persistence 
Table 2 Discontinuation rates of cholinesterase inhibitors medications at 12 and 24 months $(n=1564)$

\begin{tabular}{|c|c|c|c|c|c|c|}
\hline \multirow[t]{2}{*}{ Variable } & \multicolumn{3}{|c|}{$\begin{array}{l}\text { Discontinued by } \\
12 \text { months }\end{array}$} & \multicolumn{2}{|c|}{$\begin{array}{l}\text { Discontinued by } \\
24 \text { months }\end{array}$} & \multirow{2}{*}{$\begin{array}{l}\text { Log rank } \\
\text { probability } \\
\mathrm{Cl}\end{array}$} \\
\hline & $\mathbf{n}$ & $\%$ & Cl & $\mathbf{n}$ & $\%$ & \\
\hline Total population & $513 / 1199$ & $42.7 \%$ & (39.9\%-45.5\%) & $692 / 816$ & $84.8 \%$ & (82.3\%-87.3\%) \\
\hline $\begin{array}{l}\text { Initial type of } \\
\text { medication dispensed }\end{array}$ & & & & & & 0.2218 \\
\hline Donepezil & $279 / 673$ & $41.4 \%$ & $(37.7 \%-45.1 \%)$ & $373 / 442$ & $84.4 \%$ & (81.0\%-87.8\%) \\
\hline Rivastigmine & $115 / 250$ & $46.0 \%$ & (39.8\%-52.2\%) & I58/184 & $85.9 \%$ & (80.9\%-90.9\%) \\
\hline Galantamine & $119 / 277$ & $43.0 \%$ & $(37.1 \%-48.8 \%)$ & $162 / 190$ & $85.3 \%$ & (80.3\%-90.3\%) \\
\hline Gender & & & & & & $0.0405^{*}$ \\
\hline Female & $373 / 919$ & $40.6 \%$ & (37.4\%-43.7\%) & $515 / 615$ & $83.7 \%$ & (80.8\%-86.6\%) \\
\hline Male & $140 / 282$ & $49.6 \%$ & $(43.8 \%-55.4 \%)$ & |77/20| & $88.1 \%$ & (83.6\%-92.6\%) \\
\hline Age & & & & & & 0.1475 \\
\hline $50-69$ & $459 / 1102$ & $41.7 \%$ & $(38.7 \%-44.5 \%)$ & $629 / 740$ & $85.0 \%$ & (82.4\%-87.5\%) \\
\hline$<70$ & $54 / 100$ & $54.0 \%$ & $(44.2 \%-63.8 \%)$ & $63 / 75$ & $84.0 \%$ & (75.7\%-92.3\%) \\
\hline Race & & & & & & $<0.000 I^{*}$ \\
\hline White & $303 / 742$ & $40.8 \%$ & $(37.3 \%-44.3 \%)$ & $417 / 496$ & $84.1 \%$ & $(80.9 \%-87.3 \%)$ \\
\hline Non-white & $42 / 61$ & $68.9 \%$ & $(57.3 \%-80.5 \%)$ & $47 / 48$ & $97.9 \%$ & $(93.8 \%-101.9 \%)$ \\
\hline Setting & & & & & & 0.3202 \\
\hline Long-term care & $430 / 1037$ & $41.5 \%$ & $(38.5 \%-44.5 \%)$ & $594 / 707$ & $84.0 \%$ & (81.3\%-86.7\%) \\
\hline Community & $83 / 165$ & $50.3 \%$ & $(42.7 \%-57.9 \%)$ & $98 / 109$ & $89.9 \%$ & $(84.2 \%-95.6 \%)$ \\
\hline
\end{tabular}

*Significant result $\mathrm{p}<0.05$.

Abbreviation: $\mathrm{Cl}$, confidence interval.

Table 3 Adjusted associations between patient characteristics and discontinuation of cholinesterase inhibitors (ChEl) medications $(\mathrm{n}=1564)$

\begin{tabular}{|c|c|c|}
\hline Variable & Adjusted rate ratio & $95 \% \mathrm{Cl}$ \\
\hline \multicolumn{3}{|l|}{ Initial type of ChEl } \\
\hline \multicolumn{3}{|l|}{ medication dispensed, } \\
\hline \multicolumn{3}{|l|}{ persistence up to 365 days } \\
\hline Galantamine or rivastigmine & I.0 (reference) & \\
\hline Donepezil & 1.002 & $0.807-1.243$ \\
\hline \multicolumn{3}{|l|}{ Initial type of ChEl } \\
\hline \multicolumn{3}{|l|}{ medication dispensed, } \\
\hline \multicolumn{3}{|l|}{ persistence beyond 365 days } \\
\hline Galantamine or rivastigmine & I.0 (reference) & \\
\hline Donepezil & $0.700 *$ & $0.499-0.983$ \\
\hline \multicolumn{3}{|l|}{ Gender } \\
\hline Female & I.0 (reference) & \\
\hline Male & 1.082 & $0.877-1.335$ \\
\hline \multicolumn{3}{|l|}{ Age } \\
\hline $50-69$ years & I.0 (reference) & \\
\hline$\geq 70$ years & 0.898 & $0.672-1.202$ \\
\hline \multicolumn{3}{|l|}{ Race } \\
\hline Non-white & 1.0 (reference) & \\
\hline White & $0.594 *$ & $0.430-0.820$ \\
\hline \multicolumn{3}{|l|}{ Setting } \\
\hline Community & I.0 (reference) & \\
\hline Long term care & 0.873 & $0.672-1.135$ \\
\hline
\end{tabular}

*Significant result.

Abbreviation: $\mathrm{Cl}$, confidence interval. with donepezil than other ChEIs beyond 1 year of therapy, adjusting for gender, age, race, and living arrangements (adjusted RR =0.70; CI = 0.499-0.983; p < 0.0397). Similar rates of persistence for all ChEI medications for the first 12 months of use were observed (adjusted $R R=1.002$; $\mathrm{CI}=0.807-1.243 ; \mathrm{p}=0.9879)$.

Patients of white race were shown to have better persistence than nonwhites ( $41 \%$ vs $69 \%$ ), although this finding was based on an analysis of only $66 \%$ of the study population, as $34 \%$ of individuals had no information describing race in the available data sources. Despite the high rate of missing values for this variable, we believed that it was important to include this covariate in our analysis given the magnitude of difference in the percentages persisting, and because race has also been reported to be among factors associated with noncompliance (Balkrishnan 1998). The smaller percentage of nonwhite cases overall merits further analysis, as it is possible that nonwhite patients were less frequently prescribed ChEI medications. In the multivariate analysis, we did not find persistence rates to differ significantly when assessing by patient age, gender, or by living arrangement. Other researchers evaluating these factors have described inconsistent findings (Coons et al 1994; Balkrishnan 1998). 


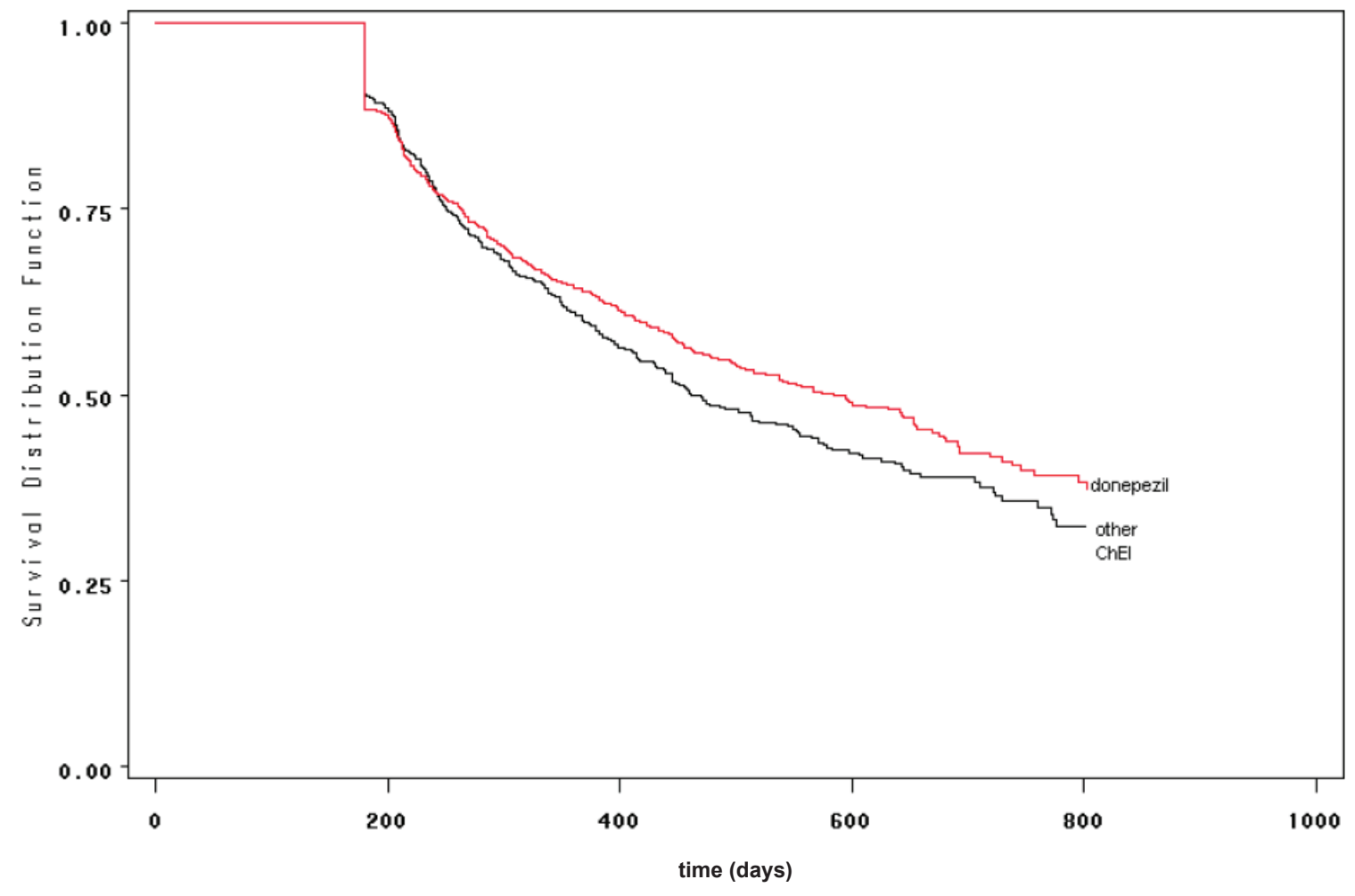

Figure I Survival curves of new users of donepezil versus other cholinesterase inhibitor medications $(\mathrm{n}=$ I564).

Two studies carried out in primary care health centers in Spain (Sicras and Rejas-Gutierrez 2004; Sicras-Mainar et al 2006) also demonstrated better persistence of donepezil than rivastigmine and galantamine. Mauskopf et al (2005) found similar rates of persistence between rivastgmine and donepezil in a retrospective community-based study. This research, however, looked at 6 months of medication persistence and did not evaluate persistence rates after 1 year. Thus, our results are consistent since we found no significant difference in persistence prior to 1 year of therapy. Furthermore, Mauskopf et al (2005) recognized that the limited sample size of rivastgmine patients might have limited the authors' ability to detect differences in persistence.

Leading reasons for discontinuation of ChEI therapy include patient or physician-perceived ineffectiveness, intolerance of side effects, or an inconvenient dosing schedule (Mauskopf et al 2005). Reported side effects include nausea, vomiting, and diarrhea (Rogers and Friedhoff 1996; Rogers et al 1998; Emre 2002; Mauskopf et al 2005). Donepezil has been reported to have better tolerability and a milder side effect profile than other ChEIs (Rogers et al 1998; Emre 2002; Inglis 2002; Wilkinson et al 2002) which might explain the observed difference in persistency rates beyond 1 year. This, nonetheless, does not explain why similar persistency rates were observed prior to 1 year, since side effects are expected to start before 1 year. Additionally, based on comparison of persistence rates, our results do not support reports that rivastigmine provides a higher magnitude of benefits than donepezil (Rogers et al 1998; Emre 2002; Inglis 2002; Wilkinson et al 2002).

The cost-effectiveness of ChEI therapy has been questioned, particularly given the high direct cost for these medications (Clegg et al 2001, 2002; Fillit and Hill 2004; Curtiss 2005; Loveman et al 2006). Outcome evaluations should also consider the quality of life of the patient and of care givers, and the importance of developing a quality of life instrument for both (Loveman et al 2006). It is difficult to quantify benefits as reported in the literature since improvements in tests such as ADAS-cog (Alzheimer's Disease Assessment Scale cognitive subscale) may not be reflected in changes of daily life (Clegg et al 2001).

Because there is currently no cure for $\mathrm{AD}$, one cannot expect the initial cognitive improvement observed in the first few months of therapy to be sustained indefinitely. However, one should expect that some patients who are treated early and persistently with $\mathrm{AD}$ medications will show less evidence of behavioral and cognitive deterioration over a period of time than one would expect in the absence of pharmacotherapy, and less decline over the long term (Geldmacher et al 2006). By reducing cognitive and functional declines over time, long-term therapy may enable patients to stay at home 
longer and decrease the burden faced by patients, caregivers, and society (Geldmacher 2003). Geldmacher et al (2003) reported that taking donepezil for 9-12 months delays nursing home placement. Hill et al ( 2002) demonstrated lower costs for $204 \mathrm{AD}$ patients in a large Medicare managed care plan on donepezil compared with 204 patients not receiving therapy with matched characteristics, where annual costs of prescriptions and medical services were $\$ 3,891$ lower for the study group. Longer term therapy ( $\geq 270$ days) also achieved lower costs compared to shorter term therapy. In our study population, $686(57.3 \%)$ patients remained on therapy for 12 months, a figure that may represent a cost-savings considering the potential outcomes described above.

Several limitations to this study can be described. Clinical data regarding diagnosis, doses used, and exact reason for discontinuation were lacking. Prescription dispensing data were used to evaluate persistence, and filling the prescription does not ensure that the drug was actually consumed. Nonetheless, refill data are considered more objective than self-report which can overestimate compliance (Choo et al 1999), and is a useful tool to assess the drug use in population-based studies (Steiner and Prochazka 1997). We could not account for use of samples or hospitalizations during a follow-up period. However, we believe that our criterion of 6 months without a prescription being dispensed to be classified as nonpersistent mitigates the potential influence of these factors because it would be difficult to obtain drug samples that cover such a long period of time and it is a long period for a continuous hospitalization. Severity of $\mathrm{AD}$ was not assessed, but including newly treated patients in the study addresses this concern to some degree, and these medications were approved for only use in mild to moderate disease as of the time of the study. We were unable to control for potential confounders pertaining to patient co-morbidities, and $34 \%$ of the population had missing values for race. Additionally, as all the patients were enrolled in a Medicaid program, they are expected to be of lower incomes and to have no co-payments for medications. This, however, might limit generalizability of the results to other populations.

While the improvements gained with the use of ChEI medications may be small or modest, sustained benefits of therapy can be realized only by patients who persist with therapy. Yet our results indicate that persistence rates with these medications are quite low. Persistence rates were higher for donepezil users compared with those who received other ChEI medication beyond 12 months, yet given the marginal difference and the limitations of our data source, we are unable to conclude that this difference suggests superiority of donepezil.

\section{Conclusions}

We found similar persistence rates for each of the three available ChEI medications, with a $42 \%$ rate of persistence at 12 months, and those dispensed donepezil were slightly more likely to persist at 24 months. While we were not able to ascertain if discontinuation was due to lack of efficacy or lack of tolerability, our analyses revealed that nearly half of patients failed to persist with ChEI therapy for at least 12 months. Our findings underscore the limitations of the ChEI medications and the urgent need for effective and tolerable therapeutic options for patients having dementia. From a drug policy perceptive, the consideration of the utility of ChEI medications should include both results from clinical trials and insights from observational studies such as ours, which reveal that for many patients ChEI medications cannot be relied upon to provide longer-term benefit in managing dementia. Reports describing measures of therapy persistence can be important to caregivers and patients in forming expectations for pharmacotherapy.

\section{References}

Applegate WB. 2002. Elderly patients' adherence to statin therapy. JAMA, 288:495-7.

Auriacombe S, Pere JJ, et al. 2002. Efficacy and safety of rivastigmine in patients with Alzheimer's disease who failed to benefit from treatment with donepezil. Curr Med Res Opin, 18:129-38.

Balkrishnan R. 1998. Predictors of medication adherence in the elderly. Clin Ther, 20:764-71

Barat I, Andreasen F, et al. 2001. Drug therapy in the elderly: what doctors believe and patients actually do. Br J Clin Pharmacol, 51:615-22.

Benner JS, Glynn RJ, et al. 2002. Long-term persistence in use of statin therapy in elderly patients. JAMA, 288:455-61.

Bergen J, Hunt G, et al. 1998. Six-month outcome following a relapse of schizophrenia. Aust N Z J Psychiatry, 32:815-22.

Birks J. 2006. Cholinesterase inhibitors for Alzheimer's disease. Cochrane Database Syst Rev, (1):CD005593.

Bullock R, Connolly C. 2002. Switching cholinesterase inhibitor therapy in Alzheimer's disease--donepezil to rivastigmine, is it worth it?. Int $J$ Geriatr Psychiatry, 17(3): 288-9.

Chin MH, Goldman L. 1997. Factors contributing to the hospitalization of patients with congestive heart failure. Am J Public Health, 87:643-8.

Choo PW, Rand CS, et al. 1999. Validation of patient reports, automated pharmacy records, and pill counts with electronic monitoring of adherence to antihypertensive therapy. Med Care, 37:846-57.

Clark CM, Karlawish JH. 2003. Alzheimer disease: current concepts and emerging diagnostic and therapeutic strategies. Ann Intern Med, 138:400-10.

Clegg A, Bryant J, et al. 2001. Clinical and cost-effectiveness of donepezil, rivastigmine and galantamine for Alzheimer's disease: a rapid and systematic review. Health Technol Assess, 5:1-137.

Clegg A, Bryant J, et al. 2002. Clinical and cost-effectiveness of donepezil, rivastigmine, and galantamine for Alzheimer's disease. A systematic review. Int J Technol Assess Health Care, 18:497-507.

Col N, Fanale JE, et al. 1990. The role of medication noncompliance and adverse drug reactions in hospitalizations of the elderly. Arch Intern Med, 150:841-5.

Coons SJ, Sheahan SL, et al. 1994. Predictors of medication noncompliance in a sample of older adults. Clin Ther, 16:110-7.

Cramer JA. 1998. Enhancing patient compliance in the elderly. Role of packaging aids and monitoring. Drugs Aging, 12:7-15. 
Curtiss FR. 2005. Does persistence with drugs for Alzheimer's disease matter? J Manag Care Pharm, 11:260-2.

Emre M. 2002. Switching cholinesterase inhibitors in patients with Alzheimer's disease. Int J Clin Pract Suppl, 127:64-72.

Ernst RL, Hay JW. 1994. The US economic and social costs of Alzheimer's disease revisited. Am J Public Health, 84:1261-4.

Ewbank DC. 1999. Deaths attributable to Alzheimer's disease in the United States. Am J Public Health, 89:90-2.

Fillit H, Cummings J. 2000. Practice guidelines for the diagnosis and treatment of Alzheimer's disease in a managed care setting: Part II--Pharmacologic therapy. Alzheimer's Disease (AD) Managed Care Advisory Council. Manag Care Interface, 13:51-6.

Fillit H, Hill J. 2004. The economic benefits of acetylcholinesterase inhibitors for patients with Alzheimer disease and associated dementias. Alzheimer Dis Assoc Disord, 18(Suppl 1):S24-9.

Fratiglioni L. 1993. Epidemiology of Alzheimer's disease. Issues of etiology and validity. Acta Neurol Scand Suppl, 145:1-70.

Geldmacher DS. 2003. Long-term cholinesterase inhibitor therapy for Alzheimer's disease: practical considerations for the primary care physician. Prim Care Companion J Clin Psychiatry, 5:251-9.

Geldmacher DS, Frolich L, et al. 2006. Realistic expectations for treatment success in Alzheimer's disease. J Nutr Health Aging, 10:417-29.

Geldmacher DS, Provenzano G, et al. 2003. Donepezil is associated with delayed nursing home placement in patients with Alzheimer's disease. $J$ Am Geriatr Soc, 51:937-44.

Giacobini E. 2000a. Cholinesterase inhibitor therapy stabilizes symptoms of Alzheimer disease. Alzheimer Dis Assoc Disord, 14:S3-10.

Giacobini E. 2000b. Cholinesterase inhibitors stabilize Alzheimer disease. Neurochem Res, 25:1185-90.

Giacobini E. 2001a. Do cholinesterase inhibitors have disease-modifying effects in Alzheimer's disease? CNS Drugs, 15:85-91.

Giacobini E. 2001b. Is anti-cholinesterase therapy of Alzheimer's disease delaying progression. Aging, 13:247-54.

Giacobini E. 2002. Long-term stabilizing effect of cholinesterase inhibitors in the therapy of Alzheimer's disease. J Neural Transm Suppl, 62:181-7.

Golden AG, Preston RA, et al. 1999. Inappropriate medication prescribing in homebound older adults. J Am Geriatr Soc, 47:948-53.

Gray SL, Mahoney JE, et al. 2001. Medication adherence in elderly patients receiving home health services following hospital discharge. Ann Pharmacother, 35:539-45.

Grutzendler J, Morris JC. 2001. Cholinesterase inhibitors for Alzheimer's disease. Drugs, 61:41-52.

Hebert LE, Beckett LA, et al. 2001. Annual incidence of Alzheimer disease in the United States projected to the years 2000 through 2050. Alzheimer Dis Assoc Disord, 15:169-73.

Hebert LE, Scherr PA, et al. 2003. Alzheimer disease in the US population: prevalence estimates using the 2000 census. Arch Neurol, 60:1119-22.

Hill JW, Futterman R, et al. 2002. The effect of donepezil therapy on health costs in a Medicare managed care plan. Manag Care Interface, 15:63-70.

Inglis F. 2002. The tolerability and safety of cholinesterase inhibitors in the treatment of dementia. Int J Clin Pract Suppl, 127:45-63.

Jackevicius CA, Mamdani M, et al. 2002. Adherence with statin therapy in elderly patients with and without acute coronary syndromes. JAMA, 288: 462-7.

Jann MW. 1998. Pharmacology and clinical efficacy of cholinesterase inhibitors. Am J Health Syst Pharm, 1(55):S22-5.

Kloszewska I. 2002. Acetylcholinesterase inhibitors-beyond Alzheimer's disease. Psychiatr Pol, 36(6 Suppl):133-41.

Lanctot KL, Herrmann N, et al. 2003. Efficacy and safety of cholinesterase inhibitors in Alzheimer's disease: a meta-analysis. CMAJ, 169:557-64.
Loveman E, Green C, et al. 2006. The clinical and cost-effectiveness of donepezil, rivastigmine, galantamine and memantine for Alzheimer's disease. Health Technol Assess, 10:iii-iv, ix-xi, 1-160.

Luscher TF, Vetter H, et al. 1985. Compliance in hypertension: facts and concepts. J Hypertens, Suppl 3(1):S3-9.

Mauskopf JA, Paramore C, et al. 2005. Drug persistency patterns for patients treated with rivastigmine or donepezil in usual care settings. J Manag Care Pharm, 11:231-51.

McDermott MM, Schmitt B, et al. 1997. Impact of medication nonadherence on coronary heart disease outcomes. A critical review. Arch Intern Med, 157:1921-9.

McDonald HP, Garg AX, et al. 2002. Interventions to enhance patient adherence to medication prescriptions: scientific review. JAMA, 288:2868-79.

Monane M, Matthias DM, et al. 1998. Improving prescribing patterns for the elderly through an online drug utilization review intervention: a system linking the physician, pharmacist, and computer. JAMA, 280:1249-52.

Paterson DL, Swindells S, et al. 2000. Adherence to protease inhibitor therapy and outcomes in patients with HIV infection. Ann Intern Med, 133:21-30.

Psaty BM, Koepsell TD, et al. 1990. The relative risk of incident coronary heart disease associated with recently stopping the use of beta-blockers. JAMA, 263:1653-7.

Rocca WA, Hofman A, et al. 1991. Frequency and distribution of Alzheimer's disease in Europe: a collaborative study of 1980-1990 prevalence findings. The EURODEM-Prevalence Research Group. Ann Neurol, 30:381-90.

Roe CM, Anderson MJ, et al. 2002. How many patients complete an adequate trial of donepezil? Alzheimer Dis Assoc Disord, 16:49-51.

Rogers SL, Farlow MR, et al. 1998. A 24-week, double-blind, placebocontrolled trial of donepezil in patients with Alzheimer's disease. Donepezil Study Group. Neurology, 50:136-45.

Rogers SL, Friedhoff LT. 1996. The efficacy and safety of donepezil in patients with Alzheimer's disease: results of a US multicentre, randomized, double-blind, placebo-controlled trial. The Donepezil Study Group. Dementia, 7:293-303.

Sicras-Mainar A, Vergara J, et al. 2006. Retrospective comparative analysis of antidementia medication persistence patterns in Spanish Alzheimer's disease patients treated with donepezil, rivastigmine, galantamine and memantine. Rev Neurol, 43:449-53.

Sicras A, Rejas-Gutierrez J. 2004. Drug-cholinesterase-inhibitors persistence patterns in treated patients with dementia of Alzheimer type: retrospective comparative analysis of donepezil, rivastigmine and galantamine]. Rev Neurol, 39:312-6.

Steiner JF, Prochazka AV. 1997. The assessment of refill compliance using pharmacy records: methods, validity, and applications. $J$ Clin Epidemiol, 50:105-16.

Sullivan SD, HazletTK. 1990. Noncompliance with medication regimens and subsequent hospitalizations: A literature analysis and cost of hospitalization estimate. J Res Pharmac Econom, 2:19-33.

Trinh NH, Hoblyn J, et al. 2003. Efficacy of cholinesterase inhibitors in the treatment of neuropsychiatric symptoms and functional impairment in Alzheimer disease: a meta-analysis. JAMA, 289: 210-6.

Tsuyuki RT, Bungard TJ. 2001. Poor adherence with hypolipidemic drugs: a lost opportunity. Pharmacotherapy, 21:576-82.

Wilkinson DG, Passmore AP, et al. 2002. A multinational, randomised, 12-week, comparative study of donepezil and rivastigmine in patients with mild to moderate Alzheimer's disease. Int J Clin Pract, 56:441-6.

Zuard EG. 2001. New treatments for Alzheimer's Disease: A review. Drug benefit trends, 13:27-40. 
